\title{
OS SUPORTES DAS IMAGENS: DA FOTOGRAFIA À IMAGEM DIGITAL
}

\section{IMAGE MEDIA: FROM PHOTOGRAPHY TO DIGITAL IMAGING}

\author{
Maria Giulia DONDERO ${ }^{1}$ \\ Everardo REYES-GARCIA ${ }^{2}$
}

Resumo: Este artigo pretende abordar a questão da forma e da substância do plano de expressão de imagens (pintura, fotografia, imagem digital). Se inicialmente a semiótica greimasiana clássica - especialmente Jean-Marie Floch (1985, 1986) e Felix Thürlemann (1982) consagrou suas reflexões à relação entre forma da expressão e forma do conteúdo (semissimbolismo), a partir dos anos 1990, Jacques Fontanille se dedicou à delicada questão da substância da expressão. Em seguida, no quadro de sua proposta de hierarquia dos níveis de pertinência de análise, Fontanille $(2005,2008)$ introduziu os conceitos de suporte formal e suporte material que permitiram pensar a relação entre a imagem como texto e a imagem como objeto. Partiremos desses trabalhos para estudar a relação estreita entre substância da expressão da imagem e as práticas de produção/recepção.

Palavras-chave: Imagens. Fotografia. Imagem Digital. Suporte Formal. Suporte Material. Tela. Plano da Expressão.

\begin{abstract}
In this article we deal with questions related to images (painting, photography, digital image) from a semiotic standpoint, more precisely the form and substance of their expression plane. Classical greimasian semiotics -mainly through the works of Jean-Marie Floch (1985, 1986) and Félix Thürlemann (1982) has concentrated on the relation between form of expression and form of content (thus in a semi-symbolic fashion). Then, in the 1990s, Jacques Fontanille started exploring the substance of expression. Later, within the framework of hierarchical levels of analysis, Fontanille (2005, 2008), introduced concepts such as material and formal support in order to distinguish between image as object and image as text. We take into account these works to study the close relationship between the substance of expression of images and the practices of production-reception.
\end{abstract}

Keywords: Images. Photography. Digital Image. Formal Support. Material Support. Screen. Expression Plane.

1 Dondero. FNRS. E-mail: mariagiulia.dondero@ulg.ac.be. ORCID ID: https://orcid.org/0000-0003-23208130 .

2 Reyes-Garcia. Université Paris 8. E-mail: everardo.reyes-garcia@univ-paris8.fr. ORCID ID: https://orcid. org/0000-0001-7123-9906. 
- | Os suportes das imagens: da fotografia à imagem digital

\section{Introdução ${ }^{3}$}

Neste artigo ${ }^{4}$, estudamos os conceitos de forma e substância da expressão sob o ponto de vista da semiótica francesa, a fim de explorar as especificidades materiais das imagens - especialmente da fotografia e da imagem digital. Para isso, primeiro retomaremos o trabalho de Jean-Marie Floch, com o objetivo de entendermos de que modo o autor abordou o conceito de forma. Em um segundo momento, faremos uma reflexão sobre a noção de substância, abordada recentemente por Jacques Fontanille (2008), a partir das noções de suporte formal e suporte material (FONTANILLE, 2005, KLOCK-FONTANILLE, 2005). Essa perspectiva nos permitirá não apenas diferenciar as noções de texto fotográfico e fotografia-objeto, mas também compreender a maneira como os conceitos de suporte formal e suporte material podem nos ajudar a compreender a imagem digital.

\section{As noções de forma e substância na semiótica da imagem}

Se nos detivermos no esquema clássico da semiótica de Hjelmslev (Figura 1), notaremos que a matéria chega à significação por meio de duas formas distintas, correspondentes aos dois planos da linguagem constitutivos da função semiótica: o plano da expressão e o plano do conteúdo.

3 Agradecemos calorosamente a Audrey Moutat pela revisão deste texto e pelos valiosos comentários.

4 Tradução de Matheus Nogueira Schwartzmann (UNESP), professor do Departamento de Linguística da Faculdade de Ciências e Letras da UNESP, câmpus de Assis (SP) e do Programa de Pós-graduação em Linguística e Língua Portuguesa da UNESP, câmpus de Araraquara (SP) e Isadora Lapetina Moran, mestranda do Programa de Pós-graduação em Linguística e Língua Portuguesa da UNESP, câmpus de Araraquara (SP). 

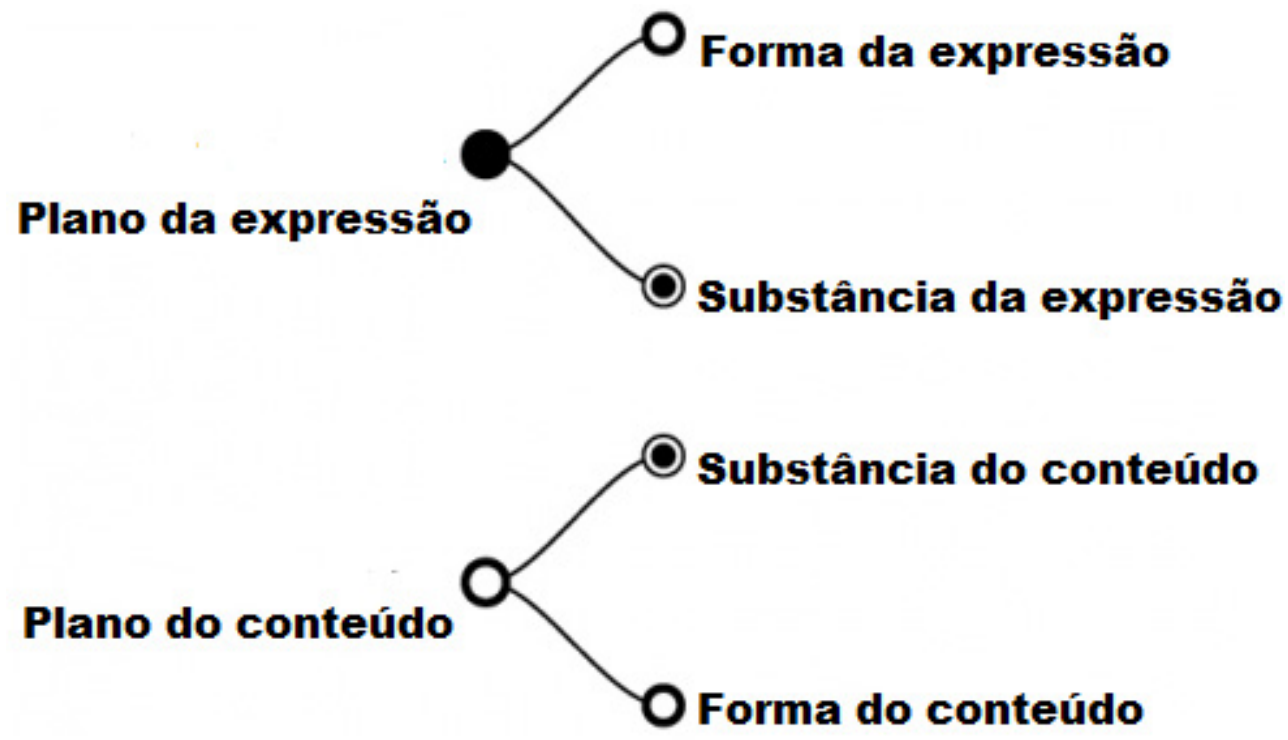

Figura 1. Planos da linguagem que constitui a função semiótica.

Fonte: Elaboração própria

A forma, tanto da expressão quanto do conteúdo, é assim descrita por Jean-Marie Floch (1985, p. 191, grifo nosso): "a forma é a organização invariante e puramente relacional de um plano, que articula a matéria sensível ou a matéria conceitual, produzindo assim a significação".

O esquema de Floch (Figura 2), extraído de sua obra Petites Mythologies de l'oeil et de l'esprit (1985), é um bom ponto de partida para esclarecer a arquitetura da forma e da substância da expressão, bem como a forma e a substância do conteúdo. 

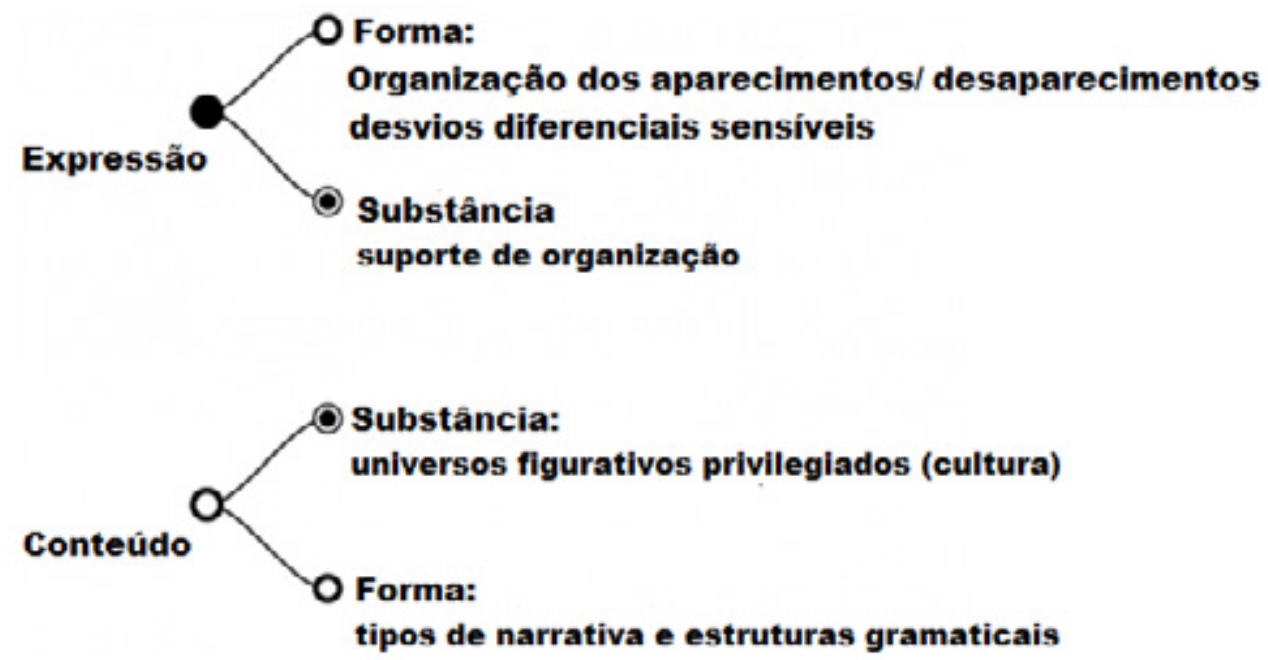

Figura 2. Esquema de Floch

Fonte: Elaboração própria a partir de Floch (1985, p. 172)

Como se pode ver nesse esquema, a substância do conteúdo refere-se aos "universos figurativos privilegiados" que se tornam pertinentes para cada cultura, enquanto a forma do conteúdo trata de "tipos de narrativa, estruturas gramaticais" bem como, poderíamos dizer, de gêneros discursivos. Diferentemente do plano da expressão das imagens, a forma do conteúdo dos textos foi estudada por vários semioticistas a partir dos anos 1980. Na verdade, no caso da imagem, o plano da expressão foi explorado exclusivamente do ponto de vista da forma da expressão, tendo sido concebido como um lugar de diferenças e de oposições. A teoria da linguagem plástica postulou que o plano da expressão seria articulado por oposições eidéticas e topológicas, assim como por uma grande diferença de potencial de energia cromática e luminosa. Conforme mostra o esquema de Floch (1985), a forma da expressão da imagem é atravessada por forças diferenciadoras de subtração e adição de forças luminosas, de intensidades cromáticas, etc.

Desde então, se a semiótica da imagem preocupou-se com os desvios diferenciais da forma da expressão, somente parcial e recentemente buscou abordar a substância do plano da expressão que, como mostra Floch (Figura 2), está relacionada ao suporte das formas, à sua "consistência", poderíamos dizer.

\section{A forma e a substância da expressão da imagem}

Conforme já afirmamos em Basso Fossali e Dondero (2011), a semiótica greimasiana não considerou em seus estudos a substância do plano da expressão, para não sair de seu 
pensamento estruturalista ${ }^{5}$. Na verdade, a semiótica da imagem soube dar conta da relação entre a forma da expressão e a forma do conteúdo por meio do desenvolvimento da noção de semissimbolismo, graças à correspondência de oposições categoriais do plano da expressão (categorias cromática, eidética e topológica) a oposições categoriais do plano do conteúdo ${ }^{6}$. Na análise da pintura $O$ mito da flor (1982), de Paul Klee, Felix Thürlemann (1982) explorou a relação entre as formas da expressão e formas do conteúdo, de maneira sistemática, permitindo que qualquer desvio diferencial sensível correspondesse a um desvio diferencial semântico. Mas restam algumas questões: o que dizer, por exemplo, do fato de tela de Klee ser coberta por gaze? Qual seria o lugar da substância nesse quadro? Thürlemann (1982) afirma que não se pode levar em consideração aquilo que se distancia das oposições topológicas, cromáticas e eidéticas, até mesmo da organização da forma e a gaze simplesmente não pode justamente ser estudada por oposições ${ }^{7}$.

Essas três categorias plásticas (topológica, cromática e eidética) são apenas um meio provisório para elucidar uma primeira organização opositiva entre zonas e subzonas da imagem, porém, elas certamente não podem por si só explicar a consistência das formas nem a sua dimensão estética. O que falta no âmbito dessa teorização é levarmos em conta a qualidade do suporte. Por exemplo, quando nos aproximamos do problema da intermidialidade e da transposição de formas de um suporte para outro, como pictural e fotográfico ${ }^{8}$, a questão se impõe de maneira decisiva.

A semiótica greimasiana deixou de lado a análise dos modos pelos quais a forma da expressão foi constituída, como se as formas não se integrassem, finalmente, a nenhuma substância. Entretanto, nas imagens pictóricas e fotográficas, o traçado está diretamente ligado ao suporte, no sentido em que o traço, enquanto aporte, manifesta-se no suporte graças à interpenetração entre ambos. Quer se trate de uma gaze ou de uma tela de madeira, isso faz a diferença.

Nesse sentido, o suporte, tanto a tela quanto o papel fotossensível, não podem ser confundidos com o fundo de uma forma ou uma figura: o suporte é o que encarna a forma, não se trata de algo que se possa descartar ou destacar para fazer emergir uma forma, e sim algo que sustenta a forma no seu ato de emergência.

\footnotetext{
5 A falta de estudos sobre a substância da expressão torna-se mais compreensível se considerarmos a literatura como primeiro objeto de estudo da semiótica francesa. A literatura nunca foi estudada do ponto de vista da escrita, ou mesmo como inscrição de traços.

6 Sobre semissimbolismo, ver Floch (1990, 1986 e 1985).

7 Le Groupe $\mu$ ensaiou uma teoria estruturalista sobre a textura: Groupe $\mu$. Traité du signe visuel. Pour une rhétorique de l'image. Paris: Seuil, 1992.

8 Ver Dondero (1999)..
} 
Em uma imagem, é difícil distinguirmos a forma da substância, pois a forma é uma organização que aparece de maneira indissociável de um suporte. Segundo Rosenthal e Visetti (1999), no artigo intitulado "Sens et temps de la Gestalt", a forma é a única configuração que pode ser transposta para outros suportes e outras substâncias. Nesse sentido, os autores ainda defendem o caráter transponível da forma: "a forma seria a invariante, o produto de esquemas dinâmicos relacionais capazes, por constituição, de operar em uma variedade indefinida de meios" (ROSENTHAL; VISETTI, 1999, p. 181, grifo nosso). Essa concepção revela claramente a maneira como a semiótica francesa tratou da forma da expressão na imagem. Mas Rosenthal e Visetti (1999, p. 181, grifo nosso) acrescentam algo de extrema importância: que essas formas estão sempre "submetidas a coerções específicas". Essas coerções dependem dos suportes das formas: como então estudá-las?

Para aprofundarmos a questão da relação entre forma e substância, tomemos um exemplo de Floch e de sua obra Les Formes de l'empreinte (1986). Floch afirma que as pinturas em guache de Matisse e a fotografia Nude $n^{\circ} 53$, de Bill Brandt, são baseadas em uma mesma estética da decupagem, até mesmo de um mesmo uso da linha de contorno, com formas rígidas e sinuosidades, à maneira das decorações egípcias, apesar das diferenças de volume, de modelo e de equilíbrio da composição. No entanto, o que podemos dizer da diferença de substância entre a tinta guache e a fotografia? Floch não diz nada a esse respeito, uma vez que qualquer referência ao suporte teria colocado em crise o percurso gerativo do conteúdo, e o percurso que conduziria, em última instância, à textualização ${ }^{9}$.

Nos anos 1980, a semiótica visual se consagrou a identificar semelhanças entre as formas da expressão no interior de diferentes tipos de imagens (picturais, esculturais, arquitetônicas etc.) para mostrar que produções visuais distantes no espaço e no tempo podem compartilhar da mesma organização subjacente (a forma invariante). Essa questão aparece como consequência da recepção do livro de Heirich Wölfflin (1966), dedicado à forma clássica e à forma barroca, compreendidas como formas simbólicas que ultrapassam os limites temporais e as distinções midiáticas ${ }^{10}$. E foi especialmente no campo da arte, que foi inclusive o primeiro campo de investigação da semiótica visual, que a consideração da

9 Estamos amparados na teoria de Jacques Fontanille apresentada em Soma et séma (2004), na qual a divisão entre a forma e a substância depende da instância enunciativa. Nesse sentido, o que é forma, de um ponto de vista, pode ser substância de outro. Em outras palavras, a forma é organizada dentro da organização da substância, porém a forma pode ser organizada por outra forma e, assim, tornar-se substância sob o ponto de vista dessa nova forma.

10 Já criticamos essa transversalidade de formas em Basso Fossali e Dondero (2011). 
substância da expressão de imagens permitiu o avanço de nossa hipótese. Para entender o processo artístico, é necessário levar em conta o tratamento da matéria. A "formação" da matéria engendra um diálogo/conflito entre o que organiza e o que é organizado, entre regras de formação e matérias que as dominam ou as acompanham. É certamente muito difícil dar conta da substância porque ela "se esconde" entre as oposições e as diferenças das formas, até mesmo entre os traços: ela é, de uma certa maneira, invisível, porque ela é já tratada, mas é ela que, em sua semi-invisibilidade, cria toda complexidade da imagem.

Iremos agora explorar o conceito de suporte, distinguindo o suporte formal do suporte material, sem esquecer que sua relação é assegurada pelo gesto, ou até mesmo pelo ritmo do gesto que enforma a matéria, seja ela pictórica, fotográfica ou computacional.

\section{Suporte material ou suporte formal: do texto ao objeto}

Para apresentar as noções de suporte formal e suporte material, tomemos o caso da fotografia, especialmente a relação entre fotografia entendida como texto e a fotografia entendida como objeto. Para isso, nos basearemos nas propostas de Fontanille (2008), apresentadas em Pratiques sémiotiques, em que a fotografia é tomada como um objeto ligado a práticas de produção/recepção distintas, mais ou menos institucionais, que a fazem circular e tornar-se interpretável.

Como acabamos de esboçar, o primeiro problema a se enfrentar é o fato de que a significação de uma imagem não depende exclusivamente da relação entre a forma da expressão e a forma do conteúdo, segundo uma relação semissimbólica. É preciso abordar a relação que cada texto, entendido como escrita, estabelece com o seu suporte. Em trabalhos anteriores (BASSO FOSSALI; DONDERO, 2011), chamamos essa escrita de "aporte". Essa concepção nos permite conceber o texto não como algo já estabilizado, mas como um conjunto de traços que buscam estabilizar-se em um suporte de inscrição. Essa perspectiva torna pertinente o gesto de produção, seja ele manual, ou mesmo sensóriomotor, ou ainda dependente de softwares e algoritmos.

Somente levando em consideração as relações entre aporte-escritura (ato de formação de formas futuras) e suporte (lugar de emergência das formas) é que se torna possível reconstruir e compreender a hierarquia" que se pode estabelecer entre textos,

11 Sobre a relação entre as interfaces de escrita e suportes, ver a contribuição de Zinna (2015). 
- | Os suportes das imagens: da fotografia à imagem digital

os objetos que acolhem esses textos e as práticas que os transferem, os segmentam e os reenquadram ${ }^{12}$.

Quanto a essa questão, é preciso dar um passo atrás. Se para a semiótica, até os anos 2000, o texto era considerado como único conjunto significante e pertinente, porque fechado e homogêneo, os trabalhos de Fontanille (2008) sobre os objetos e as práticas permitiram considerar um "conjunto significante" pertinente não somente às textualidades fechadas, mas também uma situação dada, isto é, "um segmento heterogêneo do mundo natural, configurado por uma inscrição no lugar da enunciação" (FONTANILLE, 2008, p. 22).

Devemos nos focar por um breve instante nesse "segmento heterogêneo do mundo natural". Toda a dificuldade em se estudar textos, por exemplo, fotográficos, ao mesmo tempo em que os dispositivos de apresentação/exposição que os valorizam ao longo de práticas específicas (sua disposição em museus, a mídia impressa, a tela etc.), têm origem no problema da heterogeneidade dos níveis de pertinência de análise.

O problema da heterogeneidade ${ }^{13}$ é abordado no esquema de Fontanille (2008) (Cf. Figura 3), especialmente nos níveis do texto, do objeto e da cena predicativa.

12 Parece que levantamos as mesmas questões que alguns trabalhos sobre ciências da informação e comunicação, especialmente de Bonaccorsi (2013); se por um lado, a imagem produziria significado de maneira autônoma e interna, por outro lado, os regimes midiáticos de produção forneceriam status e valor, ou seja, o que acontece, por exemplo, quando uma imagem está sujeita a mudanças de significados após a transferência de suporte e mudanças na mídia?

13 Bonaccorsi (2013) também discute o conceito de heterogeneidade quando afirma que podemos dizer que a diversidade e a heterogeneidade das fontes visuais dependem de vários níveis: o plástico e expressivo, que diz respeito às formas; da fotografia ao desenho, o enunciativo e genérico, que lida com o status social e cultural dos documentos (cartaz publicitário, fotografia amadora e filme), o documentário, que diz respeito às relações das imagens com outros conjuntos no tempo e espaço (em série, isolada). 


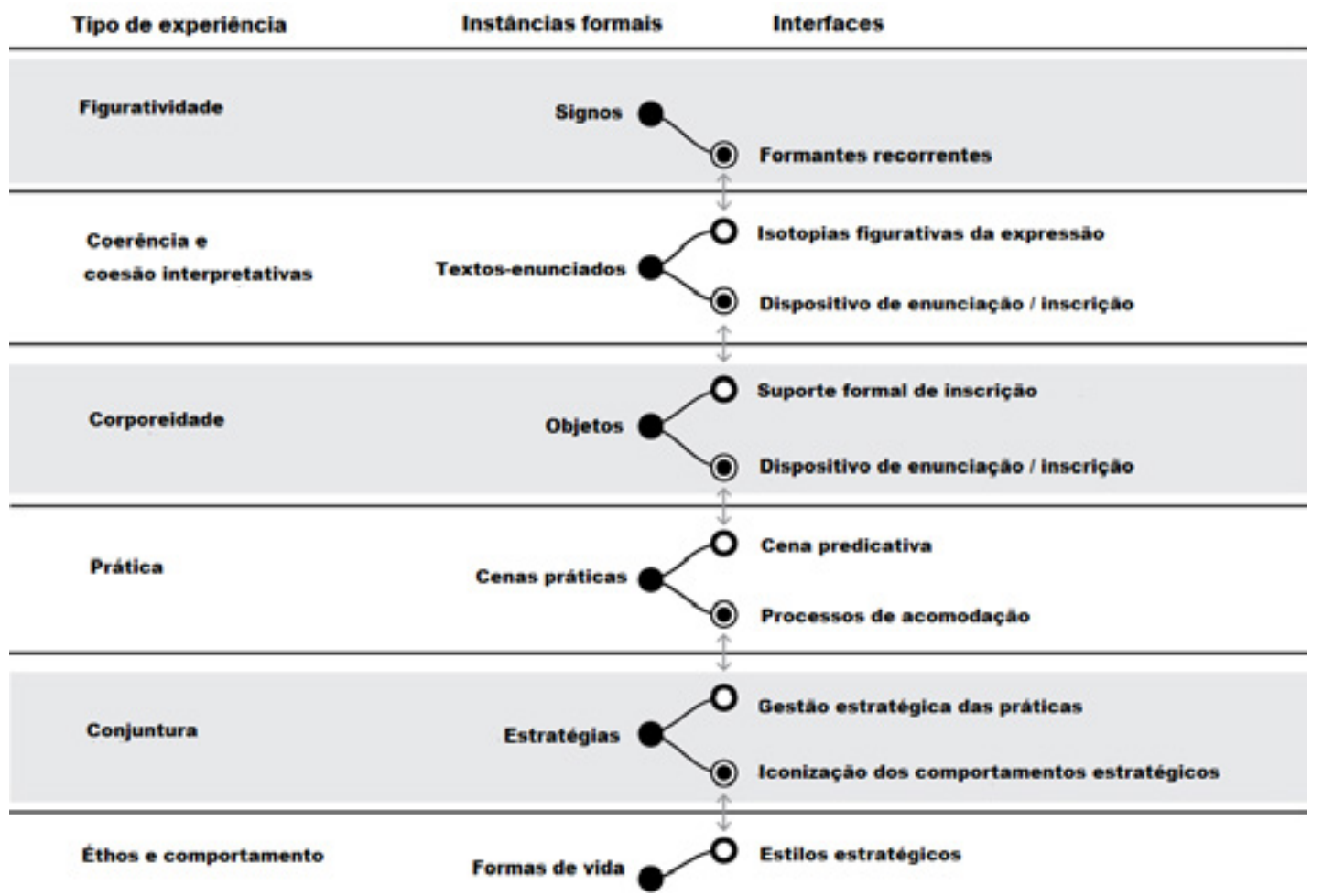

Figura 3. Esquema de Fontanille

Fonte: Elaboração própria a partir de Fontanille (2008)

Cada nível de pertinência pode ser analisado de maneira homogênea. O problema está, no entanto, na análise de um nível associado aos outros níveis. Em outras palavras, trata-se de se operar um deslocamento, ascendente ou descendente, entre níveis diferentes. Isso equivale a se colocar novamente diante da heterogeneidade, até mesmo diante de planos de imanência cujas relações devem ser examinadas.

Estudar as formas de expressão de uma fotografia (texto) é diferente de estudar a maneira como funciona seu dispositivo de apresentação (objeto), que pode ser, no caso da fotografia, uma tela associada a uma tecnologia de inscrição luminosa, ou até mesmo o que poderíamos chamar de suporte material do objeto, concebido como um subnível intermediário entre texto e objeto, a que Fontanille (2008) chama em seu esquema de "dispositivo de enunciação/inscrição".

Se identificarmos o papel fotoquímico ou tela como pertencentes à categoria dos suportes materiais, considerando as formas fotográficas como escrituras, é necessário também levarmos em conta outra mediação: a da organização dessa escritura, que podemos chamar de suporte formal. O suporte formal é o verdadeiro mediador entre as inscrições/aporte e o receptáculo/suporte material, pois ele diz respeito às regras de 
inscrição que tornam pertinente não exatamente a tecnologia da tela (suporte material), mas um outro tipo de suporte, isto é, por exemplo, oformato da página-tela.

O suporte formal nos permite focalizar a atenção sobre a disposição das inscrições sobre o suporte material, sua organização segundo um determinado tamanho, uma determinada disposição dos traços, uma determinada sintaxe, uma determinada proporção em relação à totalidade do espaço disponível e ao tipo de enquadramento. Dessa forma, podemos dizer que o nível do objeto é uma estrutura de acolhimento de inscrições composta por dois sub-níveis, ou até duas formas de mediação: o suporte formal e o suporte material.

Entre o aporte e o suporte material, o suporte formal funciona assim como mediador, que não depende nem das inscrições, nem da materialidade da tecnologia, mas que pode ser compreendido como dispositivo de ajuste entre os dois. O papel do suporte formal é, de certa maneira, "domesticar" o suporte material para que ele possa acolher as inscrições ${ }^{14}$. O suporte formal resulta de uma extração de propriedades que emanam do suporte material: o suporte material propõe linhas mestras, tendências substanciais entre as quais o suporte formal seleciona e opera uma triagem, ocultando certas propriedades do suporte material, selecionando outras.

O suporte formal é a face do objeto voltada para o texto, enquanto o suporte material é a face do objeto voltada para a prática. Se situarmos esse problema no nível de pertinência dos objetos, esses dois suportes funcionam como forma e substância: aquilo que funciona como substância no nível do texto torna-se forma ao nível do objeto, e assim sucessivamente nos níveis seguintes.

Como já abordamos o caso da fotografia em relação ao suporte formal e suporte material, examinaremos agora mais precisamente o caso das imagens digitais.

\section{Um meio instável}

Antes de expormos nossas reflexões sobre os suportes e os aportes digitais, é necessário estabelecer um ponto de partida essencial em relação à complexidade do universo das imagens digitais. Em primeiro lugar, podemos dizer que as imagens digitais constituem um meio instável, pois estão em constante desenvolvimento. A instabilidade

14 A estrutura de acolhimento das inscrições só pode ser configurada com um certo número de operações relacionadas a seu objeto material, essas operações pertencem a uma práxis (gestualidade, técnica e etc.) cuja maior ou menor sofisticação, é compatível com a lacuna que separa o objeto material de inscrição e as propriedades pertinentes do suporte formal. 
desse tipo de imagens, e as novas mídias em geral, deve-se ao seu caráter digital. De fato, as novas formas de produzir, distribuir e manipular as imagens estão diretamente associadas ao desenvolvimento tecnológico. Essas ferramentas e técnicas informáticas de que dispomos atualmente são resultados de várias decisões: econômicas, políticas, tecnológicas e culturais. Conforme afirma Wendy Chun (2013), são as visões de desenvolvedores, de empresas e de comunidades que renovam as práticas. As novas mídias são sempre novas porque se reformulam e evoluem constantemente. Há sempre novas visões e expectativas sociais e técnicas para se satisfazer.

Essa constatação nos leva a delimitar nosso espaço de trabalho. As imagens digitais das quais trataremos aqui são imagens contemporâneas, isto é, são aquelas que surgiram a partir da segunda metade dos anos 2000.

De fato, as imagens digitais de hoje não são as mesmas do século passado. As diferenças aparecem não somente no nível de sua figuração, mas também no seu nível técnico (as dimensões, a resolução, a qualidade, a compressão, a codificação e as descrições dos metadados). Por exemplo, a resolução de telas de computadores no início dos anos 2000 era de 800 x 600 pixels, enquanto hoje a resolução mais comum é de 3840 x 2160 pixels. Os fabricantes de câmeras fotográficas também aumentaram o tamanho das imagens, uma vez que no final dos anos 1990 eram de 2.0 megapixels e atualmente são de 24,2 megapixels.

Por razões práticas, escolhemos as imagens contemporâneas por ainda serem acessíveis, ao contrário de imagens cujos suportes material e formal não existem mais (alguns softwares não funcionam mais em computadores de nova geração, tais como: o Director 8, Flash 3, Photoshop 2 etc.); algumas linguagens de programação desapareceram, como SmallTalk ou HyperCard, e alguns formatos e codecs se tornaram obsoletos, como Targa (.tga)). Um estudo sobre esses ambientes é necessário e esse tem sido o objetivo de pesquisadores que se inscrevem no quadro de uma "arqueologia das mídias"15.

\section{Contextos genealógicos}

Conforme já mencionamos, uma característica das imagens digitais é sua natureza instável, que também se percebe por meio de sua experimentação. Uma imagem contemporânea (escrita de formas) está sujeita a modificações, dependendo do software e do ambiente em que se manifesta (suporte formal), o que permite combiná-la, retocá-la, transformá-la, aumentá-la com hiperlinks e metadados.

15 Ver, por exemplo, Parikka (2012) e Zielienski (2008). 
- | Os suportes das imagens: da fotografia à imagem digital

Várias imagens apresentam-se exclusivamente na forma de código de programação, sendo apenas no momento de execução do código que uma versão gráfica é produzida. Além disso, esse código de programação pode sempre ser executado de maneiras diferentes, de acordo com as diferentes organizações previstas pelo suporte formal, como é o caso das imagens generativas e das imagens fractais.

Tecnicamente falando, as imagens digitais são, de modo geral, classificadas em dois grandes tipos: imagens bitmaps e imagens vetoriais. Essa distinção refere-se à imagem descrita como objeto e como texto, em relação ao formato de armazenamento do arquivo digital. Como objeto, a imagem é descrita como uma sequência de valores de pixel, organizados de acordo com uma tabela de dados em duas dimensões. Como texto, as imagens vetoriais descrevem a imagem de acordo com expressões matemáticas que identificam as coordenadas dos pontos e dos nós em uma mesma trama matricial da tela.

Além disso, muitas vezes as imagens digitais são consideradas parte de um estatuto específico, no entanto, preferimos sustentar que se trata de um modo de existência ${ }^{16}$ diferente daquele da imagem em geral. De fato, mesmo no âmbito da produção digital, estabeleceu-se uma pluralidade de estatutos segundo os domínios de utilização, tais como, imagens artísticas, científicas, publicitárias, de entretenimento, imagens de interface (REYES, 2015) etc.

Outra classificação identifica as imagens como estáticas ou fixas (atemporais, espaciais etc., como a fotografia e a pintura), como dinâmicas ou animadas (temporais como o cinema, a televisão, o vídeo etc.) e como interativas (manipuláveis em tempo real como jogos eletrônicos, websites, softwares e algumas obras digitais). Ainda que essas distinções tenham ajudado a desenvolver técnicas específicas para cada categoria, o que nos interessa aqui não é propor uma nova categorização ontológica, mas preferencialmente buscar funcionamentos transversais a todas as imagens digitais. Isso porque podemos dizer em sentido estrito que a imagem digital nunca é fixa, uma vez que é exibida na tela do computador a uma frequência de $60 \mathrm{~Hz}$, e que ela, além disso, é sempre interativa, pois precisamos manipular os dispositivos periféricos (consoles, computadores, monitores) para visualizá-la.

É interessante destacar que a manipulação das imagens em um suporte digital reúne dois papéis de ator com frequência apresentados separadamente: o destinador e o destinatário. Como produtor de imagens, um ator A manipula um ambiente computacional, escolhe opções sintáticas dentro de dadas possibilidades. Mas esse

16 Para uma abordagem semiótica sobre modos de existência, ver Fontanille (2003, capítulo sobre enunciação). Em outra abordagem, ver Lévy (1998). 
mesmo ator A pode ser visto como o destinatário de um ator B, que é a que concebeu e construiu o programa que ele manipula. Por último, o resultado final do ator A pode ser uma imagem digital interativa, endereçada a um ator $C$ que, por sua vez, deverá manipular opções e parâmetros dos suportes formal e material.

Apesar das diferentes perspectivas, o que é importante reter, em relação às nossas considerações sobre os suportes formal e material, é o traço comum a todas as imagens digitais: elas são realizadas em um mesmo suporte material, ou seja, uma tela que exibe uma trama de pixels. Sabemos que existem muito mais pesquisas em desenvolvimento sobre o suporte das imagens digitais, porém, o seu acesso permanece reservado para especialistas de áreas que tratam de problemas como os hologramas, a realidade aumentada, as imagens astronômicas, as imagens quânticas etc.

\section{A substância da expressão das imagens digitais}

No artigo "Du support matériel au support formel" (2005), Fontanille discute o formato digital do ponto de vista da escrita e dos suportes. O autor afirma que não é suficiente identificar o arquivo digital como suporte material, distinguindo-o a da páginatela, entendida como suporte formal. A distinção é, na verdade, muito mais sutil:

No caso do arquivo digital, não existe de um lado um suporte de material eletrônico e, de outro, um suporte formal visual, mas dois objetos de escrita diferentes e completos. De um lado, temos o modo de existência "interno" e imperceptível que inclui tanto um suporte material (físico e eletrônico) quanto um suporte formal (código de programação) que gerencia as regras de inscrição e de interpretações de sinais do computador; de outro lado, o modo de existência "externo" e perceptível na interface gráfica, que comporta tanto um suporte material (uma tela, e uma tecnologia de inscrição luminosa) e um suporte formal (aquele da "página-tela"). (FONTANILLE, 2005, p. 8, grifo nosso).

O suporte formal é um conjunto de regras topológicas de orientação, dimensão, proporção e segmentação que vão condicionar e fazer significar os traços constituintes da escrita. Isso pode ocorrer com uma escrita de luz, como no caso da fotografia, com uma escrita gestual, como no caso da pintura, ou ainda, com a imagem digital, em que há um primeiro suporte formal, como a própria codificação digital, ligada à página-tela, que, por fim, pode ser entendida como um segundo suporte formal do objeto, que visualiza e regula a codificação. 
No caso do formato digital, dois suportes formais se sobrepõem. No caso da fotografia (enquanto escrita de luz) impressa, em um primeiro momento, em um suporte de papel, e, em segundo momento, exibido em uma tela. A fotografia é sobretudo uma escrita de luz sobre um suporte material, o papel fotoquímico ou o cartão de memória de uma câmera digital. A inscrição dessa luz é feita graças à mediação de um suporte formal que determina a regulação/filtragem de zonas claras e de zonas escuras, de cores, de saturação, de enquadramento etc. Mas uma vez que a imagem digital é apresentada em uma tela, no âmbito de um site, ela acaba funcionando, por sua vez, em sua integralidade, como uma escrita/aporte em relação ao suporte material-tela que a recebe e em relação à organização do espaço (o suporte formal da página-tela) que a posiciona nessa mesma tela. A fotografia como objeto completo e independente (escrita de luz sobre papel) sofre assim, na tela, uma integração midiática por meio de outro suporte formal (a páginatela), que é dotada de propriedades topológicas, no plano da expressão, e praxeológica, no plano do conteúdo, específicas. O suporte formal refere-se, assim, a regras de estabilização da fotografia como escrita-aporte na página-tela do computador, tendo em vista práticas futuras de utilização, sendo essas últimas influenciadas pelo conjunto das seleções e determinações acumuladas ao longo do percurso, indo da escrita de luz em papel fotoquímico até as regras do suporte formal da página-tela.

Encontramos, assim, pela mediação desses dois tipos de suporte, de um lado, uma ligação com a especificidade técnica de cada texto visual e, de outro, uma ligação com as práticas potencialmente presentes no suporte formal.

Isso significa que, na passagem do suporte material para o suporte formal, os possíveis usos da tecnologia sofrem uma operação de triagem que permite selecionar certas práticas como pertinentes em detrimento de outras práticas que não poderiam sustentar-se nos suportes dados.

Podemos afirmar que as três camadas identificadas - a escrita como aporte, o suporte formal e o suporte material - permitem ampliar os pontos de vista sobre o texto, até mesmo dissolvendo a ilusão de homogeneidade e estática da textualidade. Os estratos do plano da expressão, que podem ser observados em toda imagem, permitem perceber que há, na passagem do nível do texto para o nível do objeto, um processo de triagem e seleção que abre caminho para diferentes tipos de práticas de utilização e interpretação, a substância sendo orientada pelas formações que preconcebem usos possíveis/futuros. 
No que concerne a essa questão, buscamos reinterpretar o percurso gerativo da expressão (FONTANILLE, 2008) (Figura 4):

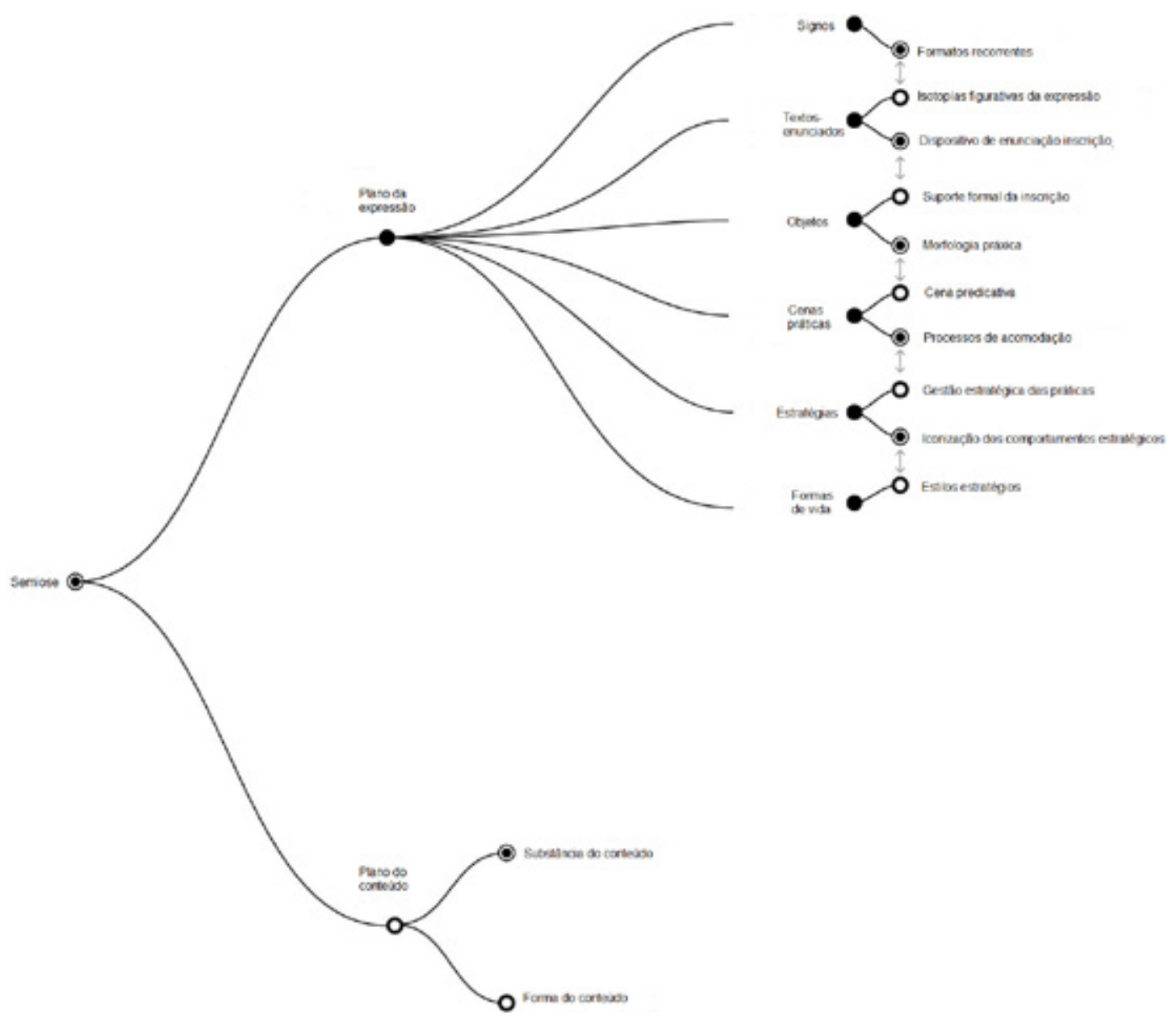

Figura 4. Reinterpretação do percurso gerativo da expressão

Fonte: Elaboração própria

Esse esquema pode ser utilizado para descrever o plano da expressão das imagens digitais. Conforme já afirmamos, nos concentramos especialmente sobre os dois níveis intermediários: o texto e o objeto. Assim, temos o seguinte esquema (Figura 5): 


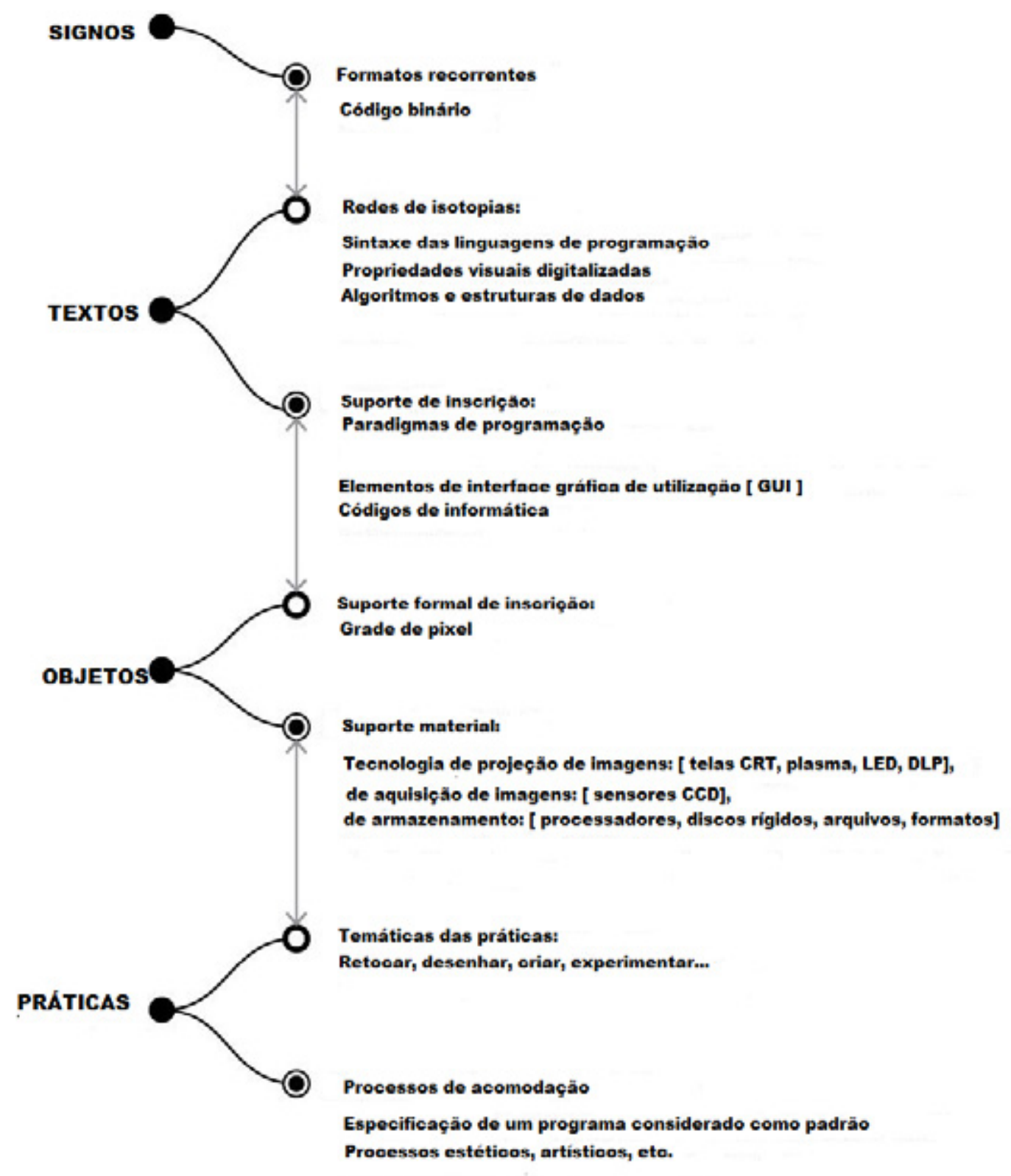

Figura 5. Adaptação dos níveis da expressão das imagens digitais.

Fonte: Elaboração própria

\section{Nível do objeto}

Em primeiro lugar, partiremos do pressuposto de que o suporte formal de base das imagens digitais é a grade de pixels em que são exibidos. Essa grade de pixels (raster grid) permite sua exibição através de procedimentos informáticos. Para melhor definirmos seu caráter essencial, propomos a noção de "pixelidade". As imagens contemporâneas, 
sejam impressas sejam projetadas numa tela, seguem linhas ordenadas de pontos sobre uma superfície. Essa arquitetura não surgiu com a imagem digital, pois ela é o último estágio de uma longa tradição em impressão e em tratamento de imagens que começou com a fotografia em meio tom, entre 1850 e 1880. Essa mesma disposição foi adotada pelas primeiras telas com função eletrônica, os monitores de tubo CRTs (tubo de raios catódicos). Assim, desde 1960, a resolução em pixels tornou-se o padrão de todas as tecnologias de projeção de imagens: LCD (display de cristal líquido), plasma e LED (diodo emissor de luz) e DLP (processamento digital de luz), e também de aquisição de imagens: os sensores CCD (dispositivo de carga acoplada) integrados, por exemplo, às câmeras fotográficas, que filtram a luz e a gravam de acordo com a grade de pixel. Sean Cubitt (2014), ainda que não adote o termo "pixilidade", afirma que este é um reflexo de nossas práticas contemporâneas, em que a comodidade se impõe sobre a qualidade: as imagens comprimidas no formato JPEG mostram cerca de 30\% das cores que o olho humano é capaz de perceber, mas elas são mais leves e adaptadas às trocas em redes digitais, como a internet (CUBITT, 2014).

Como o próprio nome sugere, a grade de pixels consiste em unidades básicas denominadas pixels (picture element). Os pixels determinam o espaço visual da imagem, seria o suporte formal que permitiria a exibição, a recuperação, a manipulação subsequentemente das formas. Trata-se de um espaço cartesiano no qual os pixels são ordenados ao longo dos eixos bidimensionais X e Y. Além disso, podemos dizer que a grade de pixels constitui a textura das imagens digitais. Os meios de comunicação em massa identificam essa textura como "pixelização", usando-a convencionalmente, por exemplo, para ocultar rostos na televisão ${ }^{17}$.

Aos pixels projetados na tela, é possível adicionar coloração, ou seja, valores cromáticos. Atualmente, um pixel é frequentemente registrado com uma profundidade de cor de 8 bits. Isso permite adicionar três camadas de cores por pixel: vermelho, verde e azul. Fala-se então em um padrão de imagem "true color", ou de 24 bits. Essa composição de cores foi introduzida pelo modelo RGB (red, green, blue), que é o modelo mais utilizado, sendo também o padrão de dispositivos de exibição ${ }^{18}$, como monitores.

17 Lembramos aqui que as imagens estão no nível do objeto do percurso gerativo da expressão. Em um nível mais profundo dos níveis de imanência, um pixel é somente o valor de uma coordenada $(x, y)$ da tabela de dados que descrevem a imagem. É, portanto, uma convenção para fins práticos, pensarmos no pixel como um "pequeno quadrado" ao passo que esse quadrado é um punhado de valores que simula o que veríamos se a imagem tivesse sido reconstruída como uma tela retangular. Se quisermos visualizar a "verdadeira" forma de um pixel, será necessário visualizar o modelo do filtro de reconstrução, por exemplo, vários pontos ligados por círculos, por exemplo, a função sinc.

18 Existem outros modelos como: escala de cinza (imagem de 4 bits): cores indexadas (imagem de 8 bits); HSL (baseada no modelo "hue, saturation and lightness", isto é, matiz, saturação e brilho); hexadecimal (modelo 
Percebemos que o gerenciamento de cores por pixel, bem como as diferentes ações de manipulação da imagem, nos remete a outro nível de análise: o texto em que diferentes componentes dão forma e substância à imagem como objeto.

\section{Nível do texto}

A face formal do nível do objeto requer a face material do nível do texto. A grade de pixels requer um suporte de inscrição que permita ao usuário manipular uma imagem digital. No nível do texto, a face formal é voltada para os signos e a face material é voltada para o objeto. Nesse contexto, os signos são 0 e 1, que constituem o código binário das mídias digitais. A face formal do texto corresponde às redes de isotopias que, nesse caso, estão associadas à sintaxe das linguagens de programação, às propriedades visuais digitalizadas (REYES, 2013), ou seja, aos algoritmos e às estruturas de dados. A face material do texto apoia-se em redes isotópicas para permitir a aplicação de paradigmas de programação, de dispositivos de interface gráfica de utilização (graphical user interface) e, em suma, códigos de informática.

As imagens digitais são somente sequências de 0 e 1 em sua estrutura interna, que, usando uma metáfora da biologia, podem ser entendidas como aquilo que constitui seu DNA. Para que sejam exploradas, as imagens devem ser encapsuladas em uma estrutura de dados por meio da linguagem de programação. Em ciência da computação, uma estrutura de dados é uma maneira particular de organização dos tipos de dados. Os tipos de dados são as unidades mínimas que uma linguagem de programação possui. Trata-se, por exemplo, de números, cadeias de caracteres, valores booleanos etc. Um exemplo de estruturas de dados é a matriz (array). Essa estrutura permite armazenar ordenadamente um conjunto de elementos que possa ser identificado por uma linguagem de programação. Outras estruturas de dados são listas, árvores e gráficos. As imagens "bitmap" são matrizes de pixel.

As ações que podem ser executadas em uma estrutura de dados dependem em grande parte de algoritmos. Estes representam a formalização de regras lógicas e matemáticas para resolver um determinado problema ou alcançar um resultado desejado. Podemos dizer que um algoritmo funciona como uma fórmula ou uma receita, isto é, uma série de etapas a serem seguidas, independentemente da linguagem de programação que será utilizada. As técnicas de processamento de imagens digitais como "pixelização"

comum para web design, a composição das cores é feita em pares de uma sequência de seis caracteres que variam de 0 à $F$, no qual $F$ é igual a 15, por exemplo \#FF0000 equivale a cor vermelha). 
ou "compressão", baseiam-se amplamente nos algoritmos. Quanto à "pixelização", um dos primeiros algoritmos empregados foi chamado de "interpolação por vizinho mais próximos", ou apenas interpolação, enquanto a compressão foi fortemente influenciada pelo popular algoritmo LZW (nomeado pelos seus criadores Lempel, Ziv e Welch).

Se sustentarmos que o suporte formal nos permite triar as potencialidades da matéria e levar a atualizações, as estruturas de dados e os algoritmos seriam assim concebíveis como sistemas de combinações potenciais, ou seja, são numericamente limitados e não são inventados cotidianamente. Por outro lado, o ritmo acelerado das inovações tecnológicas é visto justamente no momento em que algoritmos e estruturas de dados se associam.

A associação de estruturas de dados e algoritmos é chamada de programa por Niklas Wirth (1985). Em outras palavras, um programa é escrito em uma linguagem de programação a fim de que o usuário realize ações em estruturas de dados, sendo essas ações consideradas algoritmos. De fato, um programa é um elemento complexo e opaco, em que uma linha de código pode ser usada por vários tipos de dados e de algoritmos. Além disso, essas cooperações não são necessariamente lineares, pois algumas vezes um algoritmo automaticamente convoca outro, o que permite que transformações de dados possam passar despercebidas pelos usuários.

A substância da expressão do nível do texto pode, portanto, ser associada a códigos de programação. Entendemos como códigos de programação as linhas de código que dão forma às funções ou bloco de códigos e assim dão forma aos programas. Enquanto o modo de existência textual do programa é, muitas vezes, conhecido como código de programação, a versão executada ("a compilação") do programa é chamada de programa ou de software. 
- | Os suportes das imagens: da fotografia à imagem digital

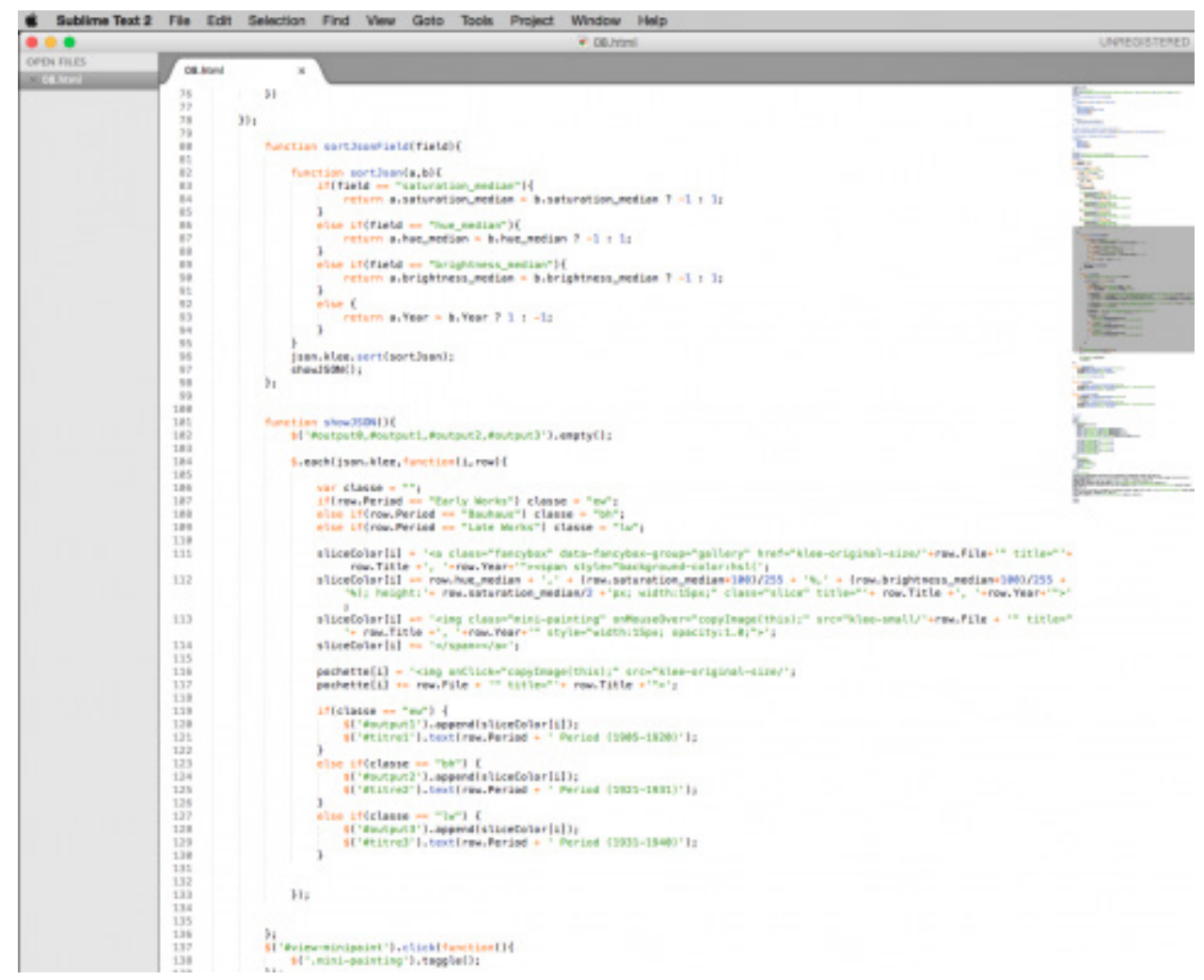

Figura 6. Exemplo de código de programação na linguagem JavaScript ${ }^{19}$

Fonte: http://journals.openedition.org/rfsic/docannexe/image/2124/img-6.png

Atualmente, temos visto uma ampliação de tipos diferentes de softwares, adaptados para diferentes usos e plataformas. Entre os programas mais difundidos, podemos citar o software de aplicação (software que é instalado no disco rígido do computador), aplicativos (aplicativos para dispositivos móveis) e aplicativos para web (aplicativos que funcionam em um servidor e que são acessíveis a partir de um navegador de internet).

\section{Nível das práticas}

O nível das práticas também mostra duas faces. De um lado, a face formal, voltada para o objeto, diz respeito às temáticas das práticas. No caso das imagens digitais, podemos identificar uma grande variedade de práticas que podem ser simuladas em um computador: desenhar, criar, colorir, retocar ou simplesmente explorar os recursos de

$19 \mathrm{O}$ arquivo foi aberto com o programa Sublime 2. As linhas de código de programação são geralmente numeradas por um melhor endereçamento e depuração. No canto superior direito, o programa mostra a ferramenta "zoom out" para todo o código, ou seja, todo o programa. A versão compilada pode ser vista em: http://ereyes.net/kleeviz/. 
um programa. Por outro lado, a face material está voltada para as estratégias, ou seja, para os processos de acomodação ou adaptação das práticas. Nesse nível, podemos observar o surgimento de práticas mais gerais que agrupam outras práticas, como o uso de algum programa considerado padrão por uma empresa ou pelo menos a sua certificação profissional (Adobe, Apple e Autodesk), ou ainda uma intervenção para fins artísticos ou estéticos (glitch art).

\section{Os aportes entre texto e objeto}

A noção de aporte nos permite compreender a relação entre texto e objeto, isto é, a relação entre o texto e o seu suporte de inscrição. O texto será entendido aqui como um ato de formação e inscrição de formas futuras.

Em um primeiro momento, observamos que os atos de inscrição associados às imagens digitais eram mediados por interfaces gráficas do usuário (GUI). Em 1984, com a introdução do computador Macintosh, a pesquisa de interação homem-máquina, iniciada na Xerox Parc por Alan Kay e seus colaboradores, abriu-se para o grande público, entrando para um certo domínio público. Os usuários não especializados não precisavam mais interagir apenas com as linhas de instruções para manipular uma imagem pois tinham a partir de então certas as convenções como o menu, o ponteiro/cursor do mouse, a barra de rolagem, os botões, os "ícones", as janelas, os painéis etc.

A maneira como o usuário manipula a interface gráfica (GUI) é uma demonstração de sua performance. O usuário estabelece um diálogo não só com o programa, mas também com os atores do design que projetaram o programa (e mais amplamente dialogaram com sua época contemporânea). Podemos assim reconhecer os nomes das funções e seus efeitos na imagem: "pixelização", "compressão" etc. Os procedimentos podem ser personalizados e as sequências de operações podem agrupar várias funções e ações. Aprende-se assim a criar e configurar figuras visuais na tela.

O exemplo a seguir (Figura 6) nos permite ver como, em um programa, as propriedades visuais de uma imagem são matematizadas e editadas por números. Essas propriedades são organizadas numa disposição topológica de recomendações de interação entre homem e máquina. 


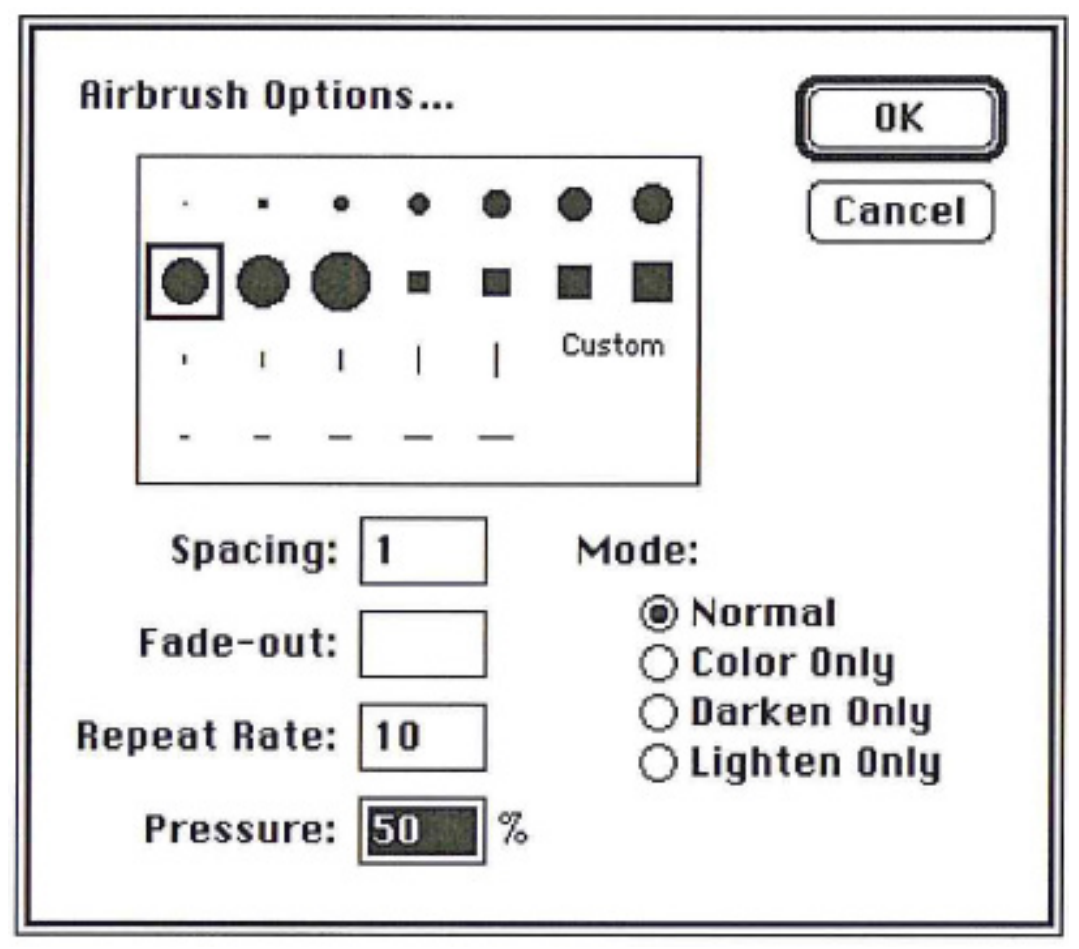

Figura 7. A interface gráfica do usuário do Photoshop 1.0: o painel de opções da ferramenta airbrush permite ajustar o tamanho do traçado e inserir valores numéricos nos espaços

Fonte: http://journals.openedition.org/rfsic/docannexe/image/2124/img-7.png

Ao mesmo tempo, as linguagens de programação não desapareceram por causa das GUls. Pelo contrário, poderíamos dizer que as GUls abriram o caminho para novos tipos de linguagem. Por exemplo, as linguagens gráficas (Hyper Card) foram introduzidas no final dos anos 1980. No final da década de 1990, as linguagens que orientavam os objetos espalharam-se e tornaram-se a norma (C++, Java). E a partir dos anos 2000, as linguagens de programação voltadas para a arte surgiram graças à explosão da World Wide Web e de comunidades de desenvolvedores independentes: Processamento (baseado na linguagem Java), Open Frame works (baseado em $\mathrm{C}++$ ) e Pure Data (uma linguagem visual).

Constatamos que as imagens digitais, enquanto inscrição, requerem uma certa mistura de competências: escrita linear (documentação e explicações do código); escrita tabular (código de computador); escrita recursiva (manipulação de GUIs); escrita diagramática (por exemplo, o programa Pure Data). A esses tipos de escrita podemos associar os tipos de leitura. Embora, por vezes, os códigos de programação não sejam facilmente compreensíveis pelos seus usuários, ainda é indispensável, do ponto de vista 
da produção, poder identificar as palavras associadas à representação e exibiç̧ão de uma imagem (data:, <img />, imagem(), PImage etc.).

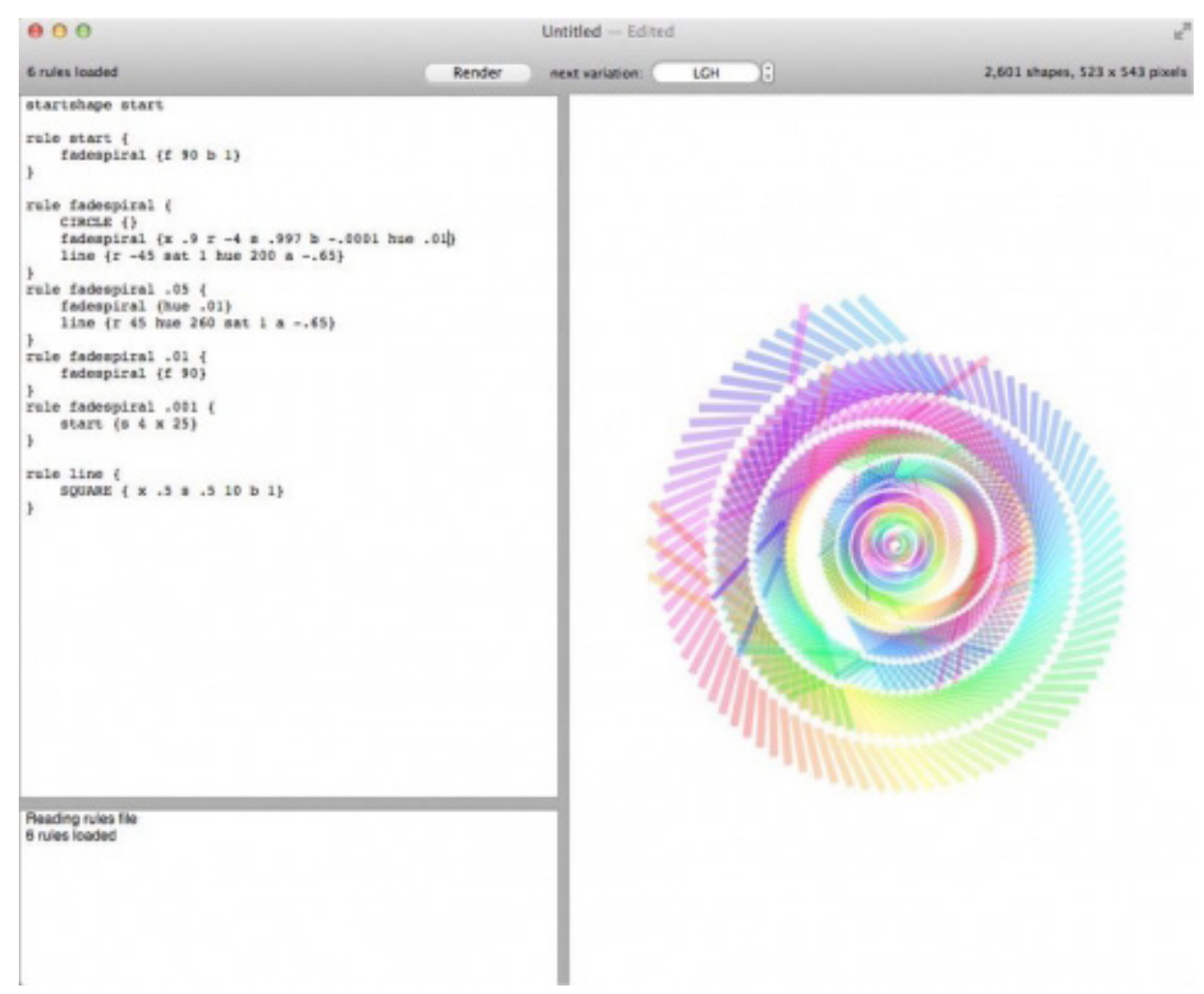

Figura 8. A interface de usuário do programa Context Free, minimalista em termos de elementos GUI. O programa permite escrever regras matemáticas fora de contexto para gerar imagens fractais

Fonte: http://journals.openedition.org/rfsic/docannexe/image/2124/img-8.jpg 


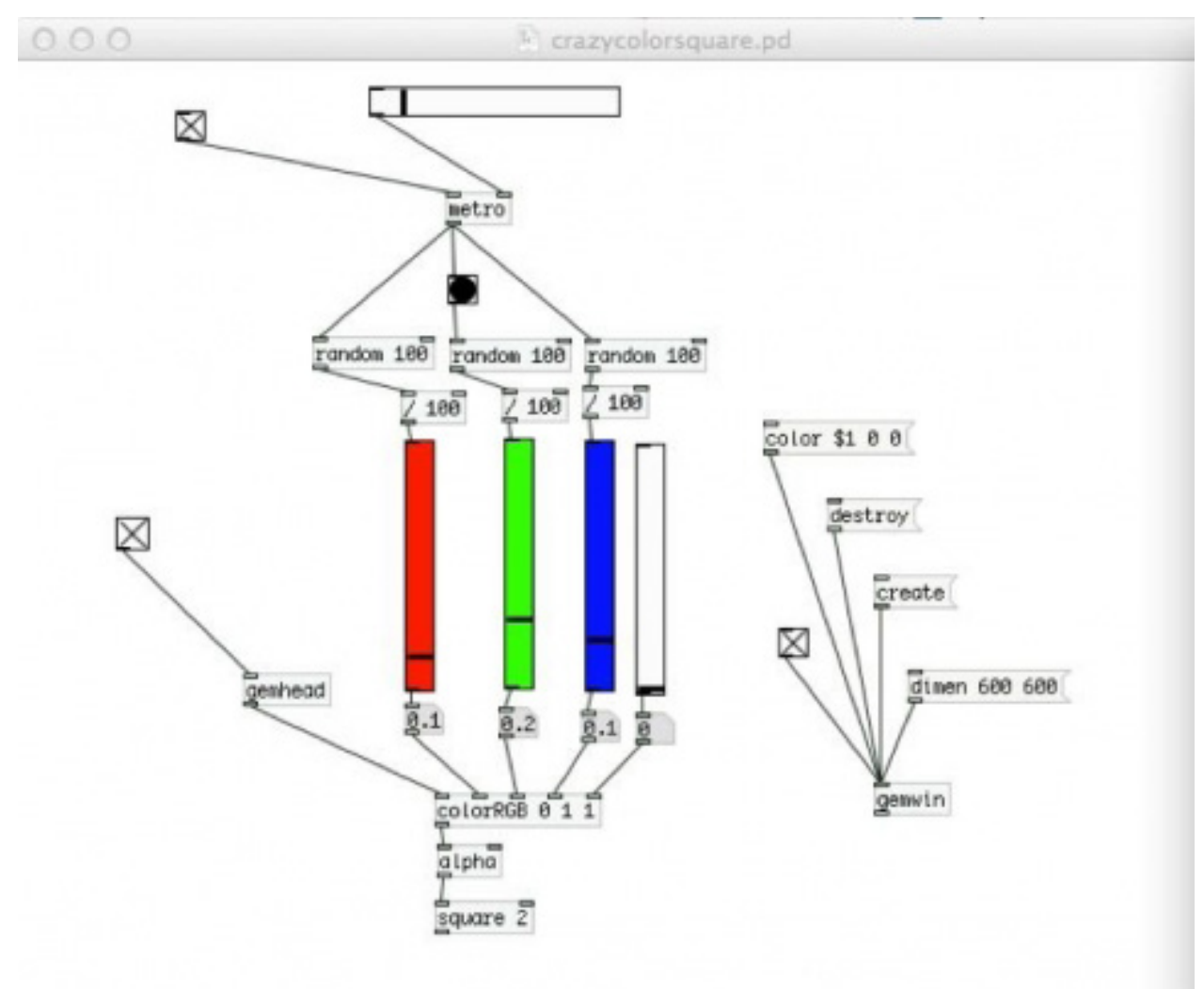

Figura 9. O software Pure Data permite ao usuário criar aplicativos audiovisuais. $\mathrm{O}$ programa é baseado em componentes que serão conectados uns aos outros. O código de programação se torna, portanto, um esquema diagramático e não mais uma série de textos

Fonte: http://journals.openedition.org/rfsic/docannexe/image/2124/img-9.jpg

\section{Conclusão: o plano da expressão das imagens digitais}

A partir dessas reflexões, queremos mostrar que o plano da expressão das imagens digitais, enquanto relação da forma da expressão e da substância da expressão, está intimamente ligado a uma propriedade das mídias digitais identificada como "variabilidade" (MANOVICH, 2011). A variabilidade nos lembra do estado instável das imagens, as possíveis combinações entre estruturas de dados e algoritmos, a multiplicidade de opções e parâmetros, o infinito potencial de versões de uma imagem. Quanto a isso, é preciso acrescentar que estas versões se tornam fixas unicamente por etapas, como a compilação e a impressão. Do contrário, elas existiriam em versões quase infinitas. E mesmo quando o conjunto de suportes formais e materiais (softwares, placas de vídeo, monitor e processador) não existirem mais, por se tornarem obsoletos, a imagem pode 
permanecer em código de programação, como texto em potencial antes do surgimento de novas formas. No entanto, uma vez que esse código torna-se visível, a nova versão nunca será idêntica a sua primeira execução

A variabilidade se apresenta em vários níveis: a concepção, a implementação, a produção, a distribuição, a navegação, o compartilhamento e a evolução adaptados a um contexto histórico. Em síntese, uma imagem digital contemporânea típica pode ser considerada como uma representação de propriedades visuais, digitalizadas ou geradas de forma nativa, tratadas estatisticamente, fisicamente armazenadas em um disco rígido, reinterpretadas e organizadas de acordo com uma grade de pixels na tela.

Acreditamos que é preciso localizar a questão dos suportes das imagens no centro das pesquisas em semiótica. A investigação dos suportes e da substância do plano de expressão nos permite não apenas especificar as proposições feitas sobre percurso gerativo da expressão, como também dar conta, de maneira estruturada, de um tipo de imagem da atualidade e de tempos futuros, que se inscreve em um modo contínuo de transformações tecnológicas e culturais. Essas transformações estão fortemente ligadas aos suportes materiais e formais e às possibilidades de escrita que eles oferecem.

\section{Referências}

BASSO FOSSALI, P.; DONDERO, M. G. Sémiotique de la photographie. Limoges: Pulim, 2011.

BONACCORSI, J. Pratiquer les images en sciences de l'Information et de la communication. Sémiose, eikones, montage. Revue française des sciences de l'information et de la communication, 2013. Disponível em: http://rfsic.revues.org/530.

CHUN, W. Programmed Visions: Software and Memory. Cambridge, MA: MIT Press, 2013.

CUBITT, S. The Practice of Light: A Genealogy of Visual Technologies from Prints to Pixels. Cambridge, MA: MIT Press, 2014.

DONDERO, M. G. Le sacré dans I'image photographique. Études sémiotiques, Paris: Hermès, 2009.

DONDERO, M. G.; FONTANILLE, J. Des images à problèmes. Le sens du visuel à l'épreuve de l'image scientifique. Limoges: Pulim, 2012. 
- | Os suportes das imagens: da fotografia à imagem digital

FLOCH, J.-M. Identités visuelles. Paris, 1990. Disponível em: 10.3917/puf.pich.2010.01. Acesso em: 20 out. 2019.

FLOCH, J.-M. Les formes de l'empreinte: Brandt, Cartier-Bresson, Doisneau, Stieglitz, Strandt. Périgueux: Fanlac, 1986.

FLOCH, J.-M. Petites mythologies de l'œil et de l'esprit. Pour une sémiotique plastique. Paris-Amsterdam: Hadès-Benjamins, 1985.

FONTANILLE, J. Pratiques sémiotiques. Paris: PUF, 2008. Disponível em: 10.3917/puf. font.2008.01. Acesso em: 20 out. 2019.

FONTANILLE, J. Du support matériel au support formel. In: ARABYAN, M.; KLOCKFONTANILLE, J. L'Écriture entre support et surface. Paris: L'Harmattan, 2005. p. 183-200. Disponível em: http://www.unilim.fr/pages_perso/jacques.fontanille/articles_pdf/ visuel/Ecritssupportsconclusion.pdf. Acesso em: 20 out. 2019.

FONTANILLE, J. Soma et séma. Figures du corps. Paris: Maisonneuve et Larose, 2004.

FONTANILLE, J. Sémiotique du discours. Limoges: Pulim, 2003.

GREIMAS, A.; COURTÈS, J. Sémiotique: dictionnaire raisonnée de la théorie du langage. Paris: Hachette, 1993.

GROUPE $\mu$. Traité du signe visuel. Pour une rhétorique de l'image. Paris: Seuil, 1992.

KLOCK-FONTANILLE, I. L'écriture entre support et surface: l'exemple des sceaux et des tablettes Hittites. In: ARABYAN, M.; KLOCK-FONTANILLE, I. (éd.). L'Écriture entre support et surface. Paris: L'Harmattan, 2005. p. 29-51.

LATOUR, B. Enquête sur les modes d'existence: Une anthropologie des Modernes. Paris: La Découverte, 2012.

LÉVY, P. Qu'est-ce que le virtuel ? Paris: La Découverte, 1998.

MANOVICH, L. The Language of New Media. Cambridge, MA: MIT Press, 2001. 
MANOVICH, L. Cultural Analytics: Visualizing Cultural Patterns in the Era of "More Media". Software Studies Initiative, 2008. Disponível em: http://manovich.net/index. php/projects/cultural-analytics-visualizing-cultural-patterns. Acesso em: 20 out. 2019.

MANOVICH, L.; REYES, E. Info-esthétique. In: VEYRAT, M. (ed). 100 Notions for Digital Art. Paris: Les Éditions de l'Immatériel, 2015.

PARIKKA, J. What is Media Archaeology. Cambridge: Polity, 2012.

REYES, E. On Visual Features and Artistic Digital Images. In: Proceedings of the ACM Conference Laval Virtual VRIC'13. New York: ACM Press, 2013.

REYES, E. La data visualisation comme image-interface. In: ARRUABARRENA, B. (coord). I2D - Information, données \& documents, v. 52, n. 2, p. 38-41, 2015.

ROSENTHAL, V.; VISETTI, Y.-M. Sens et temps de la Gestalt, in Intellectica, v. 1, n. 28, p. 147-227, 1999. Disponível em: 10.3406/intel.1999.1778. Acesso em: 20 out. 2019.

THÜRLEMANN, F. Paul Klee. Analyse sémiotique de trois peintures. Lausanne: L'Age de I'homme, 1982.

WIRTH, N. Algorithms + Data Structures = Programs. New York: Prentice Hall, 1985.

WÖLFFLIN, H. Kunstgeschichte Grundbegriffe, das Problem der Stilentwicklung in der neueren Kunst. Tradução do francês "Principes fondamentaux de l'histoire de l'art, Le problème de l'évolution du style dans l'Art modern". Paris: Gérard Montfort, 1915.

ZIELIENSKI, S. Deep Time of the Media: Toward an Archaeology of Hearing and Seeing by Technical Means. Cambridge, MA: MIT Press, 2008.

ZINNA, A. L'interface: un espace de médiation entre support et écriture. Association Française de Sémiotique, Actes du congrès AFSLux, 2015. Disponível em: http://afsemio. fr. Acesso em: 20 out. 2019. 
- | Os suportes das imagens: da fotografia à imagem digital

COMO CITAR ESTE ARTIGO: DONDERO, Maria Giulia; REYES-GARCIA, Everardo. Os suportes das imagens: da fotografia à imagem digital. Revista do GEL, v. 16, n. 2, p. 163-190, 2019. Disponível em: https://revistadogel.gel.org.br/

DOI: http://dx.doi.org/10.21165/gel.v16i2.2788

Submetido em: 06/11/2019 | Aceito em: 09/12/2019. 